We thank Geigy Pharmaceuticals and ICI Limited for financial support.

\section{References}

1 Comerford MB, Besterman EM. Relative activity of atenolol and metoprolol. Br Med f 1977;ii :260.

${ }^{2}$ Rasmussen S, Arnung K, Eskildsen PC, Nielsen PE. A comparative study of atenolol and metoprolol in the treatment of hypertension. Br f Clin Pharmacol 1981;12:887-91.

3 Scott AK, Petrie JC. Assessment of Remler blood pressure recording system. Br f Clin Pharmacol 1982;13:289-90.
4 Scales B, Copsey PB. The gas chromatographic determination of atenolol in biological samples. $\mathcal{f}$ Pharm Pharmacol 1975;27:430-3.

5 Degen PH, Reiss W. Simplified method for the determination of oxprenolol and other $\beta$-receptor blocking agents in biological fluids by gas-liquid chromatography. 7 Chromatogr 1976;121:72-5.

- Jeffers TA, Webster J, Petrie JC, Barker NP. Atenolol once-daily in hypertension. Br f Clin Pharmacol 1977;4:523-7.

7 Jeffers TA, Webster J, Reid BR, Petrie JC. Atenolol and metoprolol in mild hypertension. $\mathrm{Br}$ Med f 1978; ii :1269-70.

${ }^{8}$ Petrie JC, Jeffers TA, Robb OJ, Scott AK, Webster J. Atenolol, sustainedrelease oxprenolol, and long-acting propranolol in hypertension. Br Med F 1980;280:1573-5.

(Accepted 11 February 1982)

\title{
Blood carboxyhaemoglobin, plasma thiocyanate, and cigarette consumption: implications for epidemiological studies in smokers
}

\author{
C J VESEY, Y SALOOJEE, P V COLE, M A H RUSSELL
}

\begin{abstract}
Carboxyhaemoglobin and plasma thiocyanate concentrations were found to be significantly correlated with self-reported daily cigarette consumption in 360 smokers $(r=0.416$ and 0.412 respectively; $p<0.001)$. The extent to which inhalation patterns affected the intake of cigarette smoke constituents was determined from the partial correlation between carboxyhaemoglobin and plasma thiocyanate concentrations after the number of cigarettes smoked per day had been allowed for $(r=0 \cdot 48)$. Thus $23 \%$ of the variation in carboxyhaemoglobin and thiocyanate concentrations was accounted for by the way a cigarette was smoked and a further $21 \%$ by the number smoked a day. Furthermore, the relation between carboxyhaemoglobin or plasma thiocyanate and daily cigarette consumption was not linear but reached an asymptote at consumption rates above 25 cigarettes a day.

These results suggest that by itself daily cigarette consumption will not identify those smokers most at risk and will also underestimate the dose-response relationship between smoking and selected diseases.
\end{abstract}

\section{Introduction}

It is generally accepted that the health risks associated with smoking increase in proportion to the number of cigarettes smoked a day. This presupposes that daily cigarette consumption is an adequate index of exposure to the toxic agents in tobacco smoke. Consumption may, however, be a poor measure of dose since smokers can vary their intake of smoke in other ways-by regulating the length and depth of inhalation or by the number

\footnotetext{
Anaesthetics Laboratory, St Bartholomew's Hospital, London EC1A 7BE

C J VESEY, MSC, MIBIOL, research assistant

Y SALOOJEE, MIBIOL, research assistant

$P$ V COLE, FFARCs, consultant anaesthetist

Addiction Research Unit, Institute of Psychiatry, London E5

M A H RUSSELL, MRCP, FRCPSYCH, senior lecturer
}

and size of puffs. ${ }^{1}$ Will a true estimate of the hazards of smoking then be provided by epidemiological studies which use daily cigarette consumption to determine exposure, or does a more accurate assessment need objective measures of tobacco smoke intake?

We have measured blood carboxyhaemoglobin and plasma thiocyanate concentrations in cigarette smokers in the course of other smoking-related studies. This has provided us with data to examine the relation between dose and cigarette consumption.

\section{Subjects and methods}

The subjects studied were all healthy volunteers and were either non-smoking or smoking members of staff at St Bartholomew's Hospital or smokers attending the Maudsley Hospital. There were 360 smokers ( 178 men and 182 women) and 79 non-smokers ( 51 men and 28 women). Venous blood was taken from each subject, usually in the late morning or afternoon, for the estimation of carboxyhaemoglobin and plasma thiocyanate. Carboxyhaemoglobin concentrations were determined with an IL282 CO-Oximeter ${ }^{2}$ and plasma thiocyanate by an automated modification of the Aldridge technique. ${ }^{3}$ These procedures have been described more fully elsewhere. ${ }^{4}$

\section{Results}

The smokers were subdivided into six classes on the basis of their daily cigarette consumption. The class intervals chosen allowed for digit bias in reporting daily consumption; $49^{\circ}$ of our subjects recorded numbers as 10 or multiples thereof. Details of the number of subjects, average cigarette consumption, and mean (:SEM) carboxyhaemoglobin or plasma thiocyanate concentrations in each smoking class and in non-smokers are shown in fig 1 . The significance of the differences in mean carboxyhaemoglobin or plasma thiocyanate concentrations between adjacent classes, using the Mann-Whitney U test, is also given. The biochemical measures each showed an asymptotic relationship with daily cigarette consumption. Initially the concentrations of these compounds rose rapidly and then reached a plateau at consumption rates above 25 cigarettes a day. The increases in the mean concentrations of carboxyhaemoglobin were relatively greater than those for plasma thiocyanate, shown by the appropriate selection of scales in fig 1

The ranges of carboxyhaemoglobin and plasma thiocyanate concentrations within the six smoking classes are shown in fig 2 . The separation between the cumulative distribution curves was distinct 
in the lower consumption groups but they were much closer to one another in the higher consumption groups. This further emphasised the asymptotic relationship between the measures and confirmed that daily consumption alone was not an adequate predictor of carboxyhaemoglobin or plasma thiocyanate concentrations. We have previously established $^{4}$ that $1.6 \%$ carboxyhaemoglobin and $73.0 \mu \mathrm{mol} / \mathrm{l}$ plasma thiocyanate are the best cut-off points for discriminating between smokers and non-smokers in our laboratory. The percentages of subjects with concentrations below these values are also indicated in fig 2 .

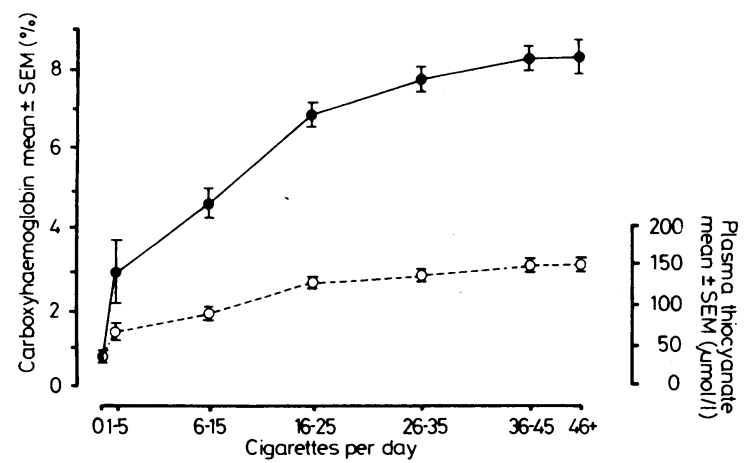

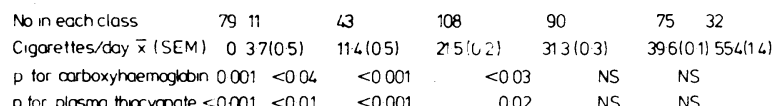

$p$ tor plasma throcyanate $<0001<001<0.001 \quad 002 \quad$ NS $\quad$ NS

FIG 1-Mean blood carboxyhaemoglobin and plasma thiocyanate concentrations in non-smokers and six smoking classes. The chosen carboxyhaemoglobin and plasma thiocyanate scales emphasise the relative increases in their respective concentrations. The number in each class together with the mean daily cigarette consumption and the significance of the differences in carboxyhaemoglobin and plasma thiocyanate concentrations between neighbouring classes are also shown.

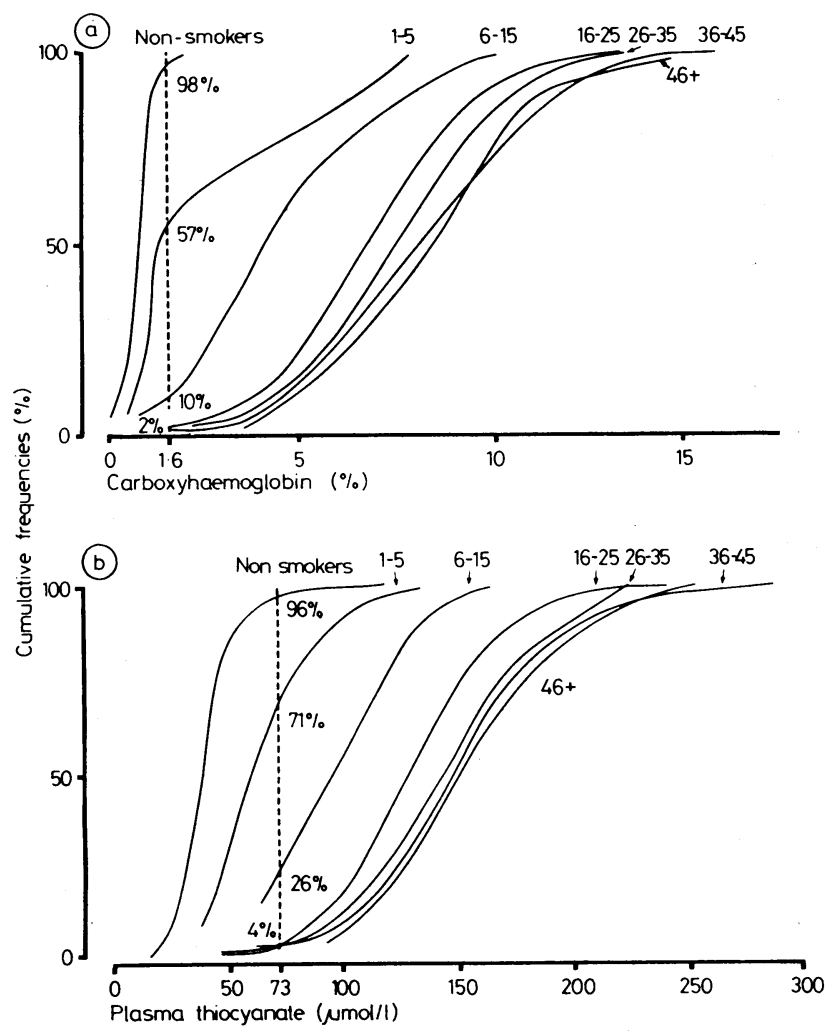

FIG 2-Cumulative frequency curves for (a) carboxyhaemoglobin and (b) plasma thiocyanate concentrations in each smoking category. The dashed lines at $1.6 \%$ carboxyhaemoglobin and $73 \mu \mathrm{mol} / 1$ plasma thiocyanate are the cut-off points for separating smokers from non-smokers. The percentage of subjects in each category who had non-smokers' concentrations, presumably because they were non-inhalers, are also shown.
The linear regression of carboxyhaemoglobin or plasma thiocyanate concentrations with daily cigarette consumption produced significant positive correlations in both instances (table I). Since the relationships between these variables were asymptotic, linear regression would have underestimated the true correlation. The data were made more nearly linear when logarithmically transformed, and as expected the correlation between log daily consumption and the biochemical measures was more positive. Carboxyhaemoglobin and plasma thiocyanate concentrations were better correlated with each other than with daily cigarette consumption.

Female smokers had significantly higher mean carboxyhaemoglobin and plasma thiocyanate concentrations than male smokers $(p<0.001)$, although there was no significant difference $(p>0.5)$ in cigarette consumption between the sexes (table II).

TABLE I-Pearson correlations of carboxyhaemoglobin and plasma thiocyanate concentrations with daily cigarette consumption

\begin{tabular}{lcc}
\hline & $\begin{array}{c}\text { Carboxyhaemoglobin } \\
\text { concentration }\end{array}$ & $\begin{array}{c}\text { Plasma thiocyanate } \\
\text { concentration }\end{array}$ \\
\hline Cigarettes per day & 0.42 & 0.41 \\
Log cigarettes per day & 0.47 & 0.46 \\
Plasma thiocyanate concentration & 0.60 & \\
\hline
\end{tabular}

TABLE II-Mean ( $上 S E M$ ) cigarette consumption, carboxyhaemoglobin, and plasma thiocyanate concentrations in men and women

\begin{tabular}{|c|c|c|c|}
\hline & $\begin{array}{c}\text { Men } \\
(n=178)\end{array}$ & $\begin{array}{c}\text { Women } \\
(\mathrm{n}=181)\end{array}$ & $\begin{array}{l}\text { Significance } \\
\text { of difference }\end{array}$ \\
\hline $\begin{array}{l}\text { Cigarettes per day } \\
\text { Carboxyhaemoglobin ( }(\text { i) } \\
\text { Plasma thiocyanate concentration }(\mu \mathrm{mol} / \mathrm{l})\end{array}$ & $\begin{array}{r}28 \cdot 8(1 \cdot 1) \\
6 \cdot 6(0 \cdot 2) \\
124 \cdot 3(3 \cdot 1)\end{array}$ & $\begin{array}{r}29 \cdot 6(0.9) \\
7.5(0.2) \\
147.4(3.4)\end{array}$ & $\begin{array}{l}\text { NS } \\
p=0.001 \\
p<0.001\end{array}$ \\
\hline
\end{tabular}

NS $=$ Not significant $;$ SFM $=$ Standard error of the mean

\section{Discussion}

Carbon monoxide and hydrogen cyanide (which is metabolised to thiocyanate) are both constituents of cigarette smoke which could contribute to the health hazards of smoking. ${ }^{5}$ If a direct dose-response relationship between the concentrations of these toxins and a disease outcome exists it could be asked how adequately would daily cigarette consumption, the most commonly used measure of dose, estimate this association. In this study daily consumption accounted for about $21 \%$ of the variation in carboxyhaemoglobin or plasma thiocyanate concentrations (table I). It would, therefore, show only a weak positive correlation with diseases related to carboxyhaemoglobin or plasma thiocyanate concentrations. Epidemiological studies using daily cigarette consumption would thus underestimate the true risks from smoking.

In non-smokers the correlation between carboxyhaemoglobin and plasma thiocyanate concentrations was 0.05 but in smokers, after daily cigarette consumption had been allowed for, the partial correlation between them was $0 \cdot 48$. This positive correlation can arise only because both these compounds are derived from inhaled cigarette smoke. This suggests that a further $23 \%$ of the variation in the blood concentrations of these substances may be explained by the smokers' puffing and inhalation habits. An American study of male smokers ${ }^{6}$ obtained correlations between daily cigarette consumption, end-expired carbon monoxide, and plasma thiocyanate concentrations similar to those that we report. The American study also showed that the conventional questionnaire estimates of dosage, such as depth of inhalation and the amount of each cigarette smoked, did not contribute significantly to the multiple regression of plasma thiocyanate and carbon monoxide. Together with our findings, this supports the view that smokers are unable to report accurately their inhalation habits. Thus a factor equally as important as daily cigarette consumption is usually ignored in many epidemiological studies. The remaining variability in 
carboxyhaemoglobin or plasma thiocyanate concentrations, which is not explained by the factors above, may be due to differences in carbon monoxide or hydrogen cyanide yields of cigarettes, excretion, and environmental or nutritional factors.

The expectation that the risks of smoking increase in proportion to daily cigarette consumption would, according to our data, be met only for those smoking up to 25 cigarettes a day. Above this number there was no significant difference in mean carboxyhaemoglobin or plasma thiocyanate concentrations between the various smoking classes (fig 1). It is relevant in this respect that two recent studies have found that the incidence of myocardial infarction in smokers reaches a plateau at about one packet of cigarettes a day. ${ }^{78}$

Many smokers achieved a high carboxyhaemoglobin or plasma thiocyanate concentration despite smoking few cigarettes. In contrast, some smokers with high cigarette consumption had low carboxyhaemoglobin or plasma thiocyanate concentrations. Figure 2 shows that $2-4 \%$ of subjects smoking 26-35 cigarettes a day are likely to have the same risk as non-smokers, while a proportion of those smoking 1-5 cigarettes a day may be at greater risk than others smoking 10 times as many cigarettes. Daily cigarette consumption will thus indicate the potential risk associated with a certain rate of smoking, but biochemical tests would actually identify those people at highest risk. Since many smokers rationalise their smoking habits by denying the relevance of impersonal health statistics to their own lives ("I don't smoke enough to get the diseases smoking is supposed to cause" or "It won't happen to me"), "9 the measurement of individual exposure could be an important factor in modifying smoking behaviour.

Our population was unusual in that mean cigarette consumption was not significantly different in men and women (table II), whereas most studies report a higher rate of smoking by men.10 The difference in mean carboxyhaemoglobin and plasma thiocyanate concentrations between the sexes requires explanation. Russell et $a l^{11}$ also found that among smokers women had higher mean carboxyhaemoglobin concentrations than men, but this difference became insignificant when smokers of plain cigarettes (mostly men) were excluded from the analysis. Smokers of unventilated filter cigarettes have higher carboxyhaemoglobin concentrations than plain cigarette smokers. ${ }^{12}$ While we do not have a record of the types of cigarettes smoked by our subjects, this seems the most likely explanation of our findings. The observed difference in plasma thiocyanate concentrations between the sexes has not previously been reported.

In conclusion, our data suggest that the measurement of either carboxyhaemoglobin or plasma thiocyanate concentrations is superior to self-reported cigarette consumption as an index of exposure to tobacco smoke. Prospective studies of smokingrelated diseases should, therefore, incorporate a biochemical estimation of smoke intake. The choice of index compound will depend on the objectives of the study. Thus carboxyhaemoglobin will not be appropriate in a study of oral cancer in primary pipe or cigar smokers. These smokers do not inhale smoke into the lungs and so have low carboxyhaemoglobin concentrations. ${ }^{13}$ For cigarette smokers, however, the easiest single measurement presently available, provided care is taken over the timing of the sample, ${ }^{14}$ is the estimation of carbon monoxide in endexpired air. ${ }^{2}$ Furthermore, it is encouraging that good correlations have been reported between carboxyhaemoglobin and blood nicotine concentrations in humans ${ }^{11}(r=0.53)$ and carboxyhaemoglobin and tar deposition in the lower respiratory tract in animals ${ }^{15}(r-0.795)$. Alveolar carbon monoxide or carboxyhaemoglobin may, therefore, also be used to indicate the relative exposure to other compounds in tobacco smoke. A limitation of biochemical markers, however, is that they reflect current smoking practices rather than those of previous years during which pathological changes may have started to take place.

We thank Mr Ewart Shaw for his valuable advice and the Joint Research Board of St Bartholomew's Hospital and the Medical Research Council for financial assistance.

\section{References}

1 Armitage AK, Hall GH, Morrison CF. Pharmacological basis for the smoking habit. Nature 1968;217:331-4.

2 Jarvis MJ, Russell MAH, Saloojee Y. Expired air carbon monoxide: a simple breath test of tobacco smoke intake. Br Med f 1980;281:484-5.

${ }^{3}$ Ellerker R, Collinson B. Use of an autoanalyser for sewage works analyses. Technicon Symposium on Automation in Analytical Chemistry 1971;133.

4 Saloojee Y, Vesey CJ, Cole PV, Russell MAH. Carboxyhaemoglobin and plasma thiocyanate: complementary indicators of smoking status? Thorax (in press).

5 Pinney JM, ed. Smoking and health. A report of the surgeon general. Bethesda, Maryland: US Department of Health, Education, and Welfare, 1979.

${ }^{6}$ Vogt TM, Selvin S, Hulley SB. Comparison of biochemical and questionnaire estimates of tobacco exposure. Prev Med 1979;8:23-33.

7 Zalokar JB, Richard JL, Claude JR. Leukocyte count, smoking, and myocardial infarction. $N$ Engl $\mathcal{F}$ Med $1981 ; 304: 465-8$.

${ }^{8}$ Holme I, Helgeland A, Hjermann I, Leren P, Lund-Larsen PG. Four and two-thirds years' incidence of coronary heart disease in middle-aged men: the Oslo study. Am F Epidemiol 1980;112:149-60.

${ }^{9}$ Green DE. Psychological factors in smoking. National Institute on Drug Abuse Research Monograph 1977;17:149-54.

${ }^{10}$ Lee PN, ed. Statistics of smoking in the United Kingdom. Research paper 1. 7 th ed and supplements. London: Tobacco Research Council, 1976.

11 Russell MAH, Jarvis M, Iyer R, Feyerabend C. Relation of nicotine yields of cigarettes to blood nicotine concentrations in smokers. $\mathrm{Br} \mathrm{Med} \mathrm{F}$ $1980 ; 281: 973-6$.

12 Wald NJ, Idle M, Boreham J, Bailey A. Inhaling habits among smokers of different types of cigarettes. Thorax $1980 ; 35: 925-8$

${ }^{13}$ Castleden CM, Cole PV. Inhalation of tobacco smoke by pipe and cigar smokers. Lancet 1973;iii:21-2.

14 Castleden CM, Cole PV. Variations in carboxyhaemoglobin levels in smokers. Br Med $\mathcal{F} 1974$;iv:736-8.

15 Binns R, Beven JL, Wilton LV, Lugton WGD. Inhalation toxicity studies on cigarette smoke. II Tobacco inhalation dosimetry studies on small laboratory animals. Toxicology 1976;6:197-206.

(Accepted 26 February 1982)

\section{OF A SCIRRHUS AND CANCER.}

A SCIRRHUS is a hard indolent tumour feated in fome of the glands; as the breafts, the arm-pits, \&c. If the tumour becomes large, unequal, of a livid, blackifh or leaden colour, and is attended with violent pain, it gets the name of an occult cancer. When the $\mathrm{fkin}$ is broken, and a fanies or ichorous matter of an abominably fotid fmell is difcharged from the fore, it is called an open or ulcerated cancer. Perfons after the age of 45 , particularly women, and thofe who lead an indolent fedentary life, are moft fubject to this difeafe.

CAUSES. - This difeafe is often owing to fuppreffed evacuations; hence it proves fo frequently fatal to women of a grofs habit, particularly old maids and widows, about the time when the menftrual flux ceafes. It may likewife be occafioned by exceffive grief, fear, anger, religious melancholy, or any of the depreffing paffions. Hence the unfortunate, the choleric, and thofe perfons who devote themfelves to a religious life in convents or monalteries, are often afflicted with it. It may alfo be occafioned by the long-continued ufe of food that is too hard of digeftion, or of an acrid nature; by barrennefs; celibacy; indolence; cold; blows; friction; pretfure; or the like. Women often fuffer from the laft of thefe by means of their ftays, which fqueeze and comprefs their breaft fo as to occafion great mifchief. Sometimes the difeafe is owing to an hereditary difpofition.

(Buchan's Domestic Medicine, i786.) 